\title{
A social work study on aggressive behavior among Iranian students
}

\author{
Mohammad Reza Iravani*
}

Department of Social Work, Islamic Azad University of Khomeinishahr, Khomeinishahr Branch, Daneshjou Blvd, Iran

\begin{tabular}{|c|c|}
\hline A R T I C L E I N F O & A B S T RAC T \\
\hline $\begin{array}{l}\text { Article history: } \\
\text { Received July } 15,2011 \\
\text { Received in Revised form } \\
\text { August, } 30,2011 \\
\text { Accepted } 30 \text { August } 2011 \\
\text { Available online } \\
10 \text { September } 2011 \\
\text { Keywords: } \\
\text { Aggressive behavior } \\
\text { Social work study } \\
\text { Gender and aggressive behavior } \\
\text { Age and aggressive behavior }\end{array}$ & $\begin{array}{l}\text { Aggressive behavior has many bad effects on people's health care and lifestyle and any attempt } \\
\text { to find the main issues influencing aggressive behavior among young students could help setup } \\
\text { appropriate programs to control and possibly reduce aggressive attitudes. The proposed study of } \\
\text { this paper performs an empirical study to find out the relationship between aggressive behavior } \\
\text { and other important factors such as gender, age, etc. The survey uses a well-known } \\
\text { questionnaire introduced by Buss and Perry (The aggression questionnaire, Journal of } \\
\text { Personality and Social Psychology, 63, 452-459, 1992). The survey distributes } 500 \\
\text { questionnaire consists of different questions based on Likert scale among } 250 \text { female and } 250 \\
\text { male students. The questionnaire consists of various questions including anger, physical } \\
\text { aggression, verbal aggression and hostility. The results indicate that while there is no } \\
\text { meaningful difference between aggression attitudes of female and male students (with p- } \\
\text { value }<0.001 \text { ), the aggressive attitudes increases among older male students but this aggressive } \\
\text { reduces among female students as they get older. }\end{array}$ \\
\hline
\end{tabular}

\section{Introduction}

During the past few decades, there have been tremendous efforts to determine influencing factors affecting aggressive attitudes among students. O'Leary et al. (2008) performed an empirical study among 2363 students from seven multiethnic high schools to investigate four issues. The first one was to assess prevalence of physical dating aggression and victimization among high school students. The second objective was to evaluate prevalence of mutual and exclusive aggression. The objective was to see whether aggression differs across ethnic groups and relationship specification and the last objective was to ascertain the likelihood of injury and breakup in individuals who believed they were the recipients of physical aggression. The research concluded that dating aggression intervention programs needed to explain physical aggression of both males and females. Since about $30 \%$ of the high school males and females reported being the recipients of physical aggression by their partners, primary prevention efforts have to occur before high school.

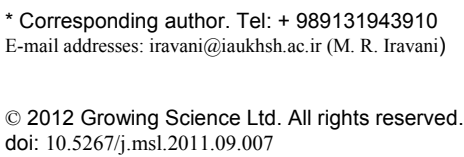


Luckner and Pianta (2011) performed another investigation to which teacher-student interactions in fifth grade classrooms were associated with peer behavior in fifth grade, accounting for prior peer functioning. In their survey, they chose 894 students from fifth grade students from the NICHD Study of early child care and youth development. The quality of teacher-student interactions in terms of emotional support, classroom organization, and instructional support was evaluated through classroom observations in fifth grade.

Peer behavior was studied via teacher report in terms of prosocial behavior, aggression, relational aggression, and a social behavior in fourth and fifth grades and classroom observations including sociable/cooperative peer behavior in third and fifth grades were considered. Multiple regression analyses disclosed that children in fifth grade classrooms with higher quality organization interactions had more positive observed interactions with their peers and lower teacher ratings of aggression and relational aggression.

Skara et al. (2008) investigated physical and relational aggression as predictors of drug use by studying gender differences among high school students. Tremblay et al. (2008) studied severity of physical aggression reported by university students by testing the interaction between trait aggression and alcohol consumption.

As part of an online study of aggression, they chose 2647 full-time undergraduate students at six Canadian universities based on aggression questionnaire (Buss \& Perry, 1992) and reported on whether they had been involved in incidents of physical aggression in the past 12 months at a (1) bar, nightclub or pub, (2) home or residence, and (3) party or social event. About one in four students claimed an incident and the scores on the physical trait aggression scale correlated significantly with severity of aggression in the three locations. Males reported higher severity than did females in the three locations. Alcohol consumption was significantly associated with severity at bars and parties but not in the home location.

Öngen (2010) investigated the relationship between narcissism and aggression among non-referred Turkish university students. They examined the relationship between narcissism and aggression in 247 university students using the Turkish versions of Buss \& Perry aggression questionnaire (BPAQ) (Buss \& Perry, 1992).

The sub-dimensions of the BPAQ were anger, physical aggression, verbal aggression and hostility. As hypothesized, regression analyses disclosed that exhibitionism was the positive predictor of physical aggression, anger and hostility. Unexpectedly, regression analyses showed that power was also the positive predictor of physical aggression, verbal aggression and anger. Kimble reformed a review on all related works associated with the relationship between aggression and violent behavior in athletics.

Valizadeh et al. (2010) investigated the effectiveness of anger management skills training on reduction of aggression in adolescents. Alvarez (2007) studied the effect of teacher preparation on responses to student aggression in the classroom. He examined the effect of teacher preparation on responses to classroom aggression using a questionnaire, which was distributed among 121 teachers employed in 11 public schools across Southwest Virginia completed.

He measured teaching characteristics and responded to vignettes depicting student aggression and using multiple regression analyses for evaluating the process by which teachers could respond to classroom aggression, and the moderating influence of teacher training. They concluded the importance of prior training in supporting classroom management.

Barth et al. (2004) performed another important study and reported that classroom environment could influence on aggression, peer relations, and academic focus. They examined how variations in social and academic classroom composition as well as the larger school context influenced behavior in a 
normative sample of children over a 2-year period. Teachers provided ratings of individual students, which were then aggregated to form teacher-based measures of classroom environment.

The proposed study of this paper investigates the relationship between aggression and other personal characteristics such as age, gender, education, etc. The orientation of this paper first presents details of the survey in section 2 and section 3 presents results of our survey. Concluding remarks are also given in the last section to summarize the contribution of this paper.

\section{Proposed study}

The proposed study of this paper uses Buss and Perry aggression questionnaire (BPAQ), which is considered as a standard method for investigating the effect of aggression. We have selected two groups of 250 people from female and male students and distributed questionnaire among them. The questionnaire was based on Likert scale (Likert, 1932) based on five different categories and the responses are analyzed based on some statistical tests.

\section{The results}

The first question is associated the participants' reaction when they are scared. Table 1 summarizes details of their responses for this question.

\section{Table 1}

The responses on whether participants leave their responsibilities when they are scared

\begin{tabular}{lcccc}
\hline Gender & \multicolumn{2}{c}{ Female } & \multicolumn{2}{c}{ Male } \\
\cline { 2 - 5 } Response & Frequency & Percentage & Frequency & Percentage \\
\hline Yes & 50 & 20 & 30 & 12 \\
No & 179 & 72 & 181 & 72 \\
No response & 21 & 8 & 39 & 16 \\
\hline Sum & 250 & 100 & 250 & 100 \\
\hline
\end{tabular}

As we can observe from Table 1, 72 percents of the participants believe they do not leave their job when they are scared. The next question is whether they can feel capable of accomplishing their duties and the responses are summarized in Table 2.

Table 2

The responses on whether participants feel they are capable of performing their educational duties

\begin{tabular}{lcccc}
\hline \multirow{2}{*}{ Render } & \multicolumn{2}{c}{ Female } & \multicolumn{2}{c}{ Male } \\
\cline { 2 - 5 } Response & Frequency & Percentage & Frequency & Percentage \\
\hline Very much & 9 & 4 & 28 & 12 \\
Much & 81 & 32 & 82 & 32 \\
Medium & 151 & 60 & 98 & 40 \\
Low & 9 & 4 & 22 & 8 \\
Very low & 0 & 0 & 11 & 4 \\
No response & 0 & 0 & 9 & 4 \\
\hline Sum & 250 & 100 & 250 & 100 \\
\hline
\end{tabular}

As we can see, most female students believe they are capable of accomplishing their duties but $16 \%$ of male students believe they are not able to accomplish their duties. The next question is associated with how they feel about their own personal physical characteristics. Table 3 shows what they think about this question. 
Table 3

The responses on how students feel on their own personal physical characteristics

\begin{tabular}{lcccc}
\hline Gender & \multicolumn{2}{c}{ Female } & \multicolumn{2}{c}{ Male } \\
\cline { 2 - 5 } Response & Frequency & Percentage & Frequency & Percentage \\
\hline Very much & 32 & 12 & 0 & 0 \\
Much & 48 & 20 & 142 & 56 \\
Medium & 161 & 64 & 78 & 32 \\
Low & 9 & 4 & 21 & 8 \\
Very low & 0 & 0 & 9 & 4 \\
No response & 0 & 0 & 0 & 0 \\
\hline Sum & 250 & 100 & 250 & 100 \\
\hline
\end{tabular}

As we can see from the results of Table 3, female students are not very much satisfied from their beauties compared with male students who are mostly satisfied on how they look. The next question we asked from our participants was whether they feel they could contribute to the society or not and Table 4 shows the results of our survey.

Table 4

The responses on whether students feel they could contribute to society or not

\begin{tabular}{lcccc}
\hline Gender & \multicolumn{2}{c}{ Female } & \multicolumn{2}{c}{ Male } \\
\cline { 2 - 5 } Response & Frequency & Percentage & Frequency & Percentage \\
\hline Very much & 10 & 4 & 41 & 16 \\
Much & 131 & 52 & 59 & 24 \\
Medium & 109 & 44 & 122 & 48 \\
Low & 0 & 0 & 21 & 8 \\
Very low & 0 & 0 & 9 & 4 \\
No response & 0 & 0 & 0 & 0 \\
\hline Sum & 250 & 100 & 250 & 100 \\
\hline
\end{tabular}

As we can observe from the results of Table 4 most female students feel they could contribute to their society but some male students feel they are not be able to contribute to their society. Another question is whether students feel their opinions are important for their family or not. Table 5 shows details of our survey.

Table 5

The responses on whether students feel their opinions are important for their family or not

\begin{tabular}{lcccc}
\hline Gender & \multicolumn{2}{c}{ Female } & \multicolumn{2}{c}{ Male } \\
\cline { 2 - 5 } Response & Frequency & Percentage & Frequency & Percentage \\
\hline Very much & 31 & 12 & 61 & 24 \\
Much & 91 & 36 & 99 & 40 \\
Medium & 108 & 44 & 81 & 32 \\
Low & 12 & 4 & 0 & 0 \\
Very low & 8 & 4 & 9 & 4 \\
No response & 0 & 0 & 0 & 0 \\
\hline Sum & 250 & 100 & 250 & 100
\end{tabular}

It is clear from Table 5 that most of the participants believe their opinions play important role among their families. Next question is about whether the participants get confused when they are encountered with a difficulty and the Table 6 summarizes the responses on this question. 
Table 6

The responses on whether students get confused when they are encountered with challenges

\begin{tabular}{lcccc}
\hline Gender & \multicolumn{2}{c}{ Female } & \multicolumn{2}{c}{ Male } \\
\cline { 2 - 5 } Response & Frequency & Percentage & Frequency & Percentage \\
\hline Very much & 41 & 16 & 22 & 8 \\
Much & 49 & 20 & 38 & 16 \\
Medium & 71 & 28 & 71 & 28 \\
Low & 69 & 28 & 99 & 40 \\
Very low & 20 & 8 & 20 & 8 \\
No response & 0 & 0 & 0 & 0 \\
\hline Sum & 250 & 100 & 250 & 100 \\
\hline
\end{tabular}

It seems that most female students feel confused when they are encountered with some challenges while this situation is better with male students. One important question in our survey is whether participants could do well when the face with anger and Table 7 shows the results of our survey. As we can see from the results of Table 7, 68 percents of the female participants believed they could sleep while only 48 percents of male participants could sleep well. This means that challenging incidents could influence male students more than female students.

Table 7

The responses on whether participants could sleep in case of facing with anger

\begin{tabular}{lcccc}
\hline Gender & \multicolumn{2}{c}{ Female } & \multicolumn{2}{c}{ Male } \\
\cline { 2 - 5 } Response & Frequency & Percentage & Frequency & Percentage \\
\hline Yes & 78 & 32 & 132 & 52 \\
No & 172 & 68 & 118 & 48 \\
No response & 0 & 0 & 0 & 0 \\
\hline Sum & 250 & 100 & 250 & 100 \\
\hline
\end{tabular}

Our survey also asked the participant on how they feel responsible on their duties and the responses are summarized in Table 8.

Table 8

The responses on how participants feel responsible

\begin{tabular}{lcccc}
\hline Gender & \multicolumn{2}{c}{ Female } & \multicolumn{2}{c}{ Male } \\
\cline { 2 - 5 } Response & Frequency & Percentage & Frequency & Percentage \\
\hline Very much & 49 & 20 & 51 & 20 \\
Much & 161 & 64 & 169 & 68 \\
Medium & 31 & 12 & 9 & 4 \\
Low & 9 & 4 & 0 & 0 \\
Very low & 0 & 0 & 11 & 4 \\
No response & 0 & 0 & 10 & 4 \\
\hline Sum & 250 & 100 & 250 & 100 \\
\hline
\end{tabular}

According to our survey, 84 percents of the female participants believe they are highly responsible for what they do while 88 percents of the male students feel responsible for what they do. We have also asked our participants on how sensitive about what they do and while 88 percents of the female students feel highly sensitive for what they do but 92 percents of male students feel highly sensitive on what they do. Another question was whether they could concentrate on their educational studies when they were met with aggressive attitudes and while 76 percents of female students believed they could not concentrate on their educational program, only 68 percents of male students said they could not concentrate on their educational program. Another question was whether students feel accountable on questions their parents asked them and while 84 percents of female students claimed 
they considered themselves accountable from the questions their parents ask and only 76 percents of the male students reported that they feel themselves accountable for what they do. One important question is the level of tolerance against failure and the results of our survey are summarized in Table 9.

Table 9

The responses on the level of tolerance against failure

\begin{tabular}{lcccc}
\hline Gender & \multicolumn{2}{c}{ Female } & \multicolumn{2}{c}{ Male } \\
\cline { 2 - 5 } Response & Frequency & Percentage & Frequency & Percentage \\
\hline Very much & 39 & 16 & 31 & 12 \\
Much & 101 & 40 & 119 & 48 \\
Medium & 91 & 36 & 71 & 28 \\
Low & 9 & 4 & 9 & 4 \\
Very low & 0 & 0 & 10 & 4 \\
No response & 10 & $\% 4$ & 10 & 4 \\
\hline Sum & 250 & 100 & 250 & 100 \\
\hline
\end{tabular}

As we can observe from the results of Table 9 while 96 percents of female students had relatively medium to high level of tolerance this number is 80 percent for male students. One of the necessary questions is whether students ask permission from their parents to do important jobs or not and both groups responded that they both get their parents' permissions before they do important jobs. Table 10 shows the results of our survey.

Table 10

The responses on whether students get parents' permission

\begin{tabular}{lcccc}
\hline \multirow{2}{*}{ Render } & \multicolumn{2}{c}{ Female } & \multicolumn{2}{c}{ Male } \\
\cline { 2 - 5 } Response & Frequency & Percentage & Frequency & Percentage \\
\hline Very much & 48 & 20 & 11 & 4 \\
Much & 52 & 20 & 49 & 20 \\
Medium & 122 & 48 & 131 & 52 \\
Low & 18 & 8 & 19 & 8 \\
Very low & 0 & 0 & 21 & 8 \\
No response & 10 & 4 & 9 & 4 \\
\hline Sum & 250 & 100 & 250 & 100 \\
\hline
\end{tabular}

As we can observe from the results of Table 10, 40 percents of the female students quite agreed to get their parents' permission while only 24 percents of male student agreed to get their parents' permission. One of important factors for reducing stress and anger from students is to have emotional support on behalf of their parents.

In our survey, while only 56 percents of female students claimed to have such support, 60 percents of the male students believed that their parents emotionally support them. Another question we asked from the participants was whether parents express their condolences in case students were encountered with unpleasant incidents and the results of our survey are summarized in Table 11.

While 72 percents of the male participants quite agreed, their parents express their passions in bad events only 52 percents of the female participants received such support. Self-confidence is one of the necessary factors for reducing tension among students. Table 12 shows the results of our survey. 
Table 11

The responses on whether students' parents express their condolences and passion in bad events

\begin{tabular}{lcccc}
\hline Gender & \multicolumn{2}{c}{ Female } & \multicolumn{2}{c}{ Male } \\
\cline { 2 - 5 } Response & Frequency & Percentage & Frequency & Percentage \\
\hline Very much & 29 & 12 & 31 & 12 \\
Much & 101 & 40 & 159 & 64 \\
Medium & 71 & 28 & 21 & 8 \\
Low & 9 & 4 & 19 & 8 \\
Very low & 11 & 4 & 20 & 8 \\
No response & 29 & 12 & 0 & 0 \\
\hline Sum & 250 & 100 & 250 & 100 \\
\hline
\end{tabular}

Table 12

The responses on whether students have confidence on their jobs

\begin{tabular}{lcccc}
\hline Gender & \multicolumn{2}{c}{ Female } & \multicolumn{2}{c}{ Male } \\
\cline { 2 - 5 } Response & Frequency & Percentage & Frequency & Percentage \\
\hline Very much & 39 & 16 & 61 & 24 \\
Much & 101 & 40 & 119 & 48 \\
Medium & 51 & 20 & 52 & 20 \\
Low & 19 & 8 & 10 & 4 \\
Very low & 11 & 4 & 8 & 4 \\
No response & 29 & 12 & 0 & 0 \\
\hline Sum & 250 & 100 & 250 & 100 \\
\hline
\end{tabular}

As we can observe from the results of Table 12, over 76 percents of the participants believed they had enough confidence on doing their jobs.

\section{Table 13}

The responses on whether participants could considered themselves angry or not

\begin{tabular}{lcccc}
\hline Gender & \multicolumn{2}{c}{ Female } & \multicolumn{2}{c}{ Male } \\
\cline { 2 - 5 } Response & Frequency & Percentage & Frequency & Percentage \\
\hline Yes & 190 & 76 & 240 & 96 \\
No & 29 & 12 & 10 & 4 \\
No response & 31 & 0 & 0 & 0 \\
\hline Sum & 250 & 100 & 250 & 100 \\
\hline
\end{tabular}

We asked our participants on whether they considered themselves as angry people or not and Table 13 shows the results of our survey. As we can see from the results of Table while 76 percents of the female participants considered themselves as angry people, this number is 96 percents for male students.

We have performed different analysis on whether the female students get angrier than male students and the results of our statistical test did not confirm such relationship with 99 percent confidence. However, aggressive attitude increases among male students as they get older with 95 percent confidence but female students get less angry as they get older. We also test other hypothesis as to whether female students feel more nerves than male students do or female students have better social relationships with society or their parents and we found no meaningful relationship. 


\section{Conclusion}

In this paper, we have presented an empirical analysis to see the relationship between aggression and other important factors such as age, gender, etc. The survey implemented a well-known questionnaire introduced by Buss and Perry and distributed 500 questionnaire consists of different questions based on Likert scale among 250 female and 250 male students. The questionnaire consisted of various questions including anger, physical aggression, verbal aggression and hostility. The results indicated that while there is no meaningful difference between aggression attitudes of female and male students (with p-value $<0.001$ ), the aggressive attitudes increases among older male students but this aggressive reduces among female students as they get older.

\section{Acknowledgment}

The author would like to thank Islamic Azad University for their financial support on this project. The author also grateful for constructive comments received from the anonymous referees on earlier version of this working paper.

\section{References}

Alvarez, H.K. (2007). The impact of teacher preparation on responses to student aggression in the classroom. Teaching and Teacher Education, 23(7), 1113-1126.

Buss, A. H., \& Perry, M. (1992). The aggression questionnaire. Journal of Personality and Social Psychology, 63, 452-459.

Barth, J.M., Dunlap, S.T., Dane, H., Lochman, J.E., \& Wells, K.C. (2004). Classroom environment influences on aggression, peer relations, and academic focus. Journal of School Psychology, 42(2), 115-133.

Kimble, N.B., Russo, S.A., Bergman, B. G., \& Galindo, V.H. (2010). Revealing an empirical understanding of aggression and violent behavior in athletics. Aggression and Violent Behavior, $15(6), 446-462$.

Likert, R. (1932). A Technique for the Measurement of Attitudes. Archives of Psychology, 140, 1-55.

Luckner, A.E., \& Pianta, R.C. (2011). Teacher-student interactions in fifth grade classrooms: Relations with children's peer behavior. Journal of Applied Developmental Psychology, 32(5), 257-266.

O'Leary, K.D., Slep, A.M.S., Avery-Leaf, S., \& Cascardi, M. (2008). Gender differences in dating aggression among multiethnic high school students. Journal of Adolescent Health, 42(5), 473-479.

Öngen, D.E. (2010). Relationships between narcissism and aggression among non-referred Turkish university students. Procedia - Social and Behavioral Sciences, 5, 410-415.

Skara, S., Pokhrel, P., Weiner, M.D., Sun, P., Dent, C.W., \& Sussman, S. (2008). Physical and relational aggression as predictors of drug use: Gender differences among high school students. Addictive Behaviors, 33(12), 1507-1515.

Tremblay, P.F., Graham, K., \& Wells, S. (2008). Severity of physical aggression reported by university students: A test of the interaction between trait aggression and alcohol consumption. Personality and Individual Differences, 45(1), 3-9.

Valizadeh, S., Berdi Ozouni Davaji, R., \& Nikamal, M. (2010).The effectiveness of anger management skills training on reduction of aggression in adolescents. Procedia - Social and Behavioral Sciences, 5, 1195-1199. 